\title{
Multiculturalismo em educação: 0 atendimento escolar de alunos bolivianos e descendentes
}

\author{
Multiculturalism in education: the school attendance \\ of Bolivian and descendant students
}

\author{
Elaine Teresinha Dal Mas Dias \\ Pós-doutoranda em Educação, Arte e História da Cultura pela \\ Universidade Presbiteriana Mackenzie. Professora do curso de \\ graduação em Psicologia e do Programa de Pós-Graduação em \\ Educação na Universidade Nove de Julho. São Paulo - SP - Brasil \\ elaine.mas@uni9.pro.br
}

João Clemente Souza Neto

Pós-doutor em Sociologia Clínica pela Pontifícia Universidade Católica de São Paulo. É professor adjunto, pesquisador e orientador no Programa de PósGraduação em Educação, Arte e História da Cultura e no curso de graduação em Pedagogia da Universidade Presbiteriana Mackenzie. São Paulo - SP - Brasil joao.souza@mackenzie.br

Resumo: Pesquisa de abordagem qualitativa em andamento, objetiva a observação e análise das relações interpessoais e educativas, entre docentes e alunos imigrantes bolivianos e descendentes, e entre os demais alunos do ensino fundamental II, dos $8^{\circ}$ e $9^{\circ}$ anos, em sala de aula e nas dependências comuns de uma escola estadual da região central de São Paulo. Baseia-se nos diferentes modelos de multiculturalismo, em especial, o assimilacionista, diferencialista e interativo ou intercultural. O método empregado nessa etapa foi o observacional sistemático, com registro de campo. Os resultados mostraram que há um distanciamento entre alunos bolivianos e descendentes e docentes, e com outros alunos, fenômenos que possibilitam, somente, uma integração por estarem em situação de exclusão e sem alteração da hegemonia social. A imperceptibilidade desses alunos é evidente e há uma restrita configuração de estratégias de alterações do cenário.

Palavras-chave: Bolivianos. Relação Socioeducativas. Integração.

\begin{abstract}
A qualitative, ongoing study aims at observing and analyzing interpersonal and educational relationships between teachers and students, Bolivian immigrants and descendants and among the other students from the elementary school II, 8th and 9th grade, in the classroom and in the common dependencies of a state school in the central region of São Paulo. It is based on the different models of multiculturalism, especially the assimilationist, differential and interactive or intercultural. The method used at this stage was the systematic observational, with field record. The results showed that there is a gap between Bolivian and descendant students and teachers, and with other students, phenomena that only allow integration because they are in a situation of exclusion and without changing social hegemony. The imperceptibility of these students is evident and there is a restricted configuration of strategies for scenario changes.
\end{abstract}

Keywords: Bolivians. Socio-educational relationship. Integration. 


\section{Introdução}

A colonização portuguesa em território brasileiro figura como uma das primeiras ações e contatos com os povos originários e com a diferença. A chegada dos africanos - escravizados e silenciados -, deu esteio a um processo de miscigenação que conformou as principais características da população ampliada, gradualmente, com a ancoragem de outras nacionalidades. Somos, portanto, uma nação fincada por movimentos imigratórios e migratórios aportados em espaços regionais construídos por necessidades, afinidades e/ou proximidades, que estruturaram um Estado multicultural. No entanto, a coexistência entre culturas distintas não ocorreu sem tensões e ambivalências vinculadas à cor da pele, à religião, aos atributos do outro, ao gênero, à integração do excluído, às projeções conscientes ou inconscientes, à política, e gerou cisões abissais entre pessoas e entre grupos, e expôs peculiaridades humanas que transitam entre a perversão e a crueldade, a benevolência e a tolerância.

O multiculturalismo que fundamenta este artigo é entendido como ação ou tática que acena com transformações e modificações de cunho populacional e cultural decorrentes de diferenças de raça, etnia, gênero, idade, religião e/ ou classe social (MOREIRA e CANDAU, 2011), e se condensam sob três eixos: o assimilacionista, o diferencialista e o interativo ou intercultural.

O assimilacionista assenta-se na integração dos grupos em situação de exclusão, sem alteração da sociedade predominante, bem como dos princípios, regras, juízos, mentalidades e saberes considerados soberanos; o diferencialista, enfatiza o respeito às diferenças, com o endosso da existência de locais para livre expressão; e o interativo ou intercultural sublinha a relação entre os diversos grupos culturais participantes de uma sociedade e mostra-se a mais apropriada à edificação de sociedades democráticas, com capacidade de vincular políticas de igualdade, identidade e identificação, em um processo de construção e reconstrução contínuos. (CANDAU, 2012; 2011).

O multiculturalismo em educação, ao visar os procedimentos didáticospedagógicos, vincula-se à Lei no 8069 do Estatuto de Criança e do Adolescente - ECA, que oficializa, em seu Art. $5^{\circ}$ das Disposições Preliminares, que "Nenhuma criança ou adolescente será objeto de qualquer forma de negligência, discriminação, violência, crueldade e opressão, punido na forma da lei qualquer atentado, 
por ação ou omissão, aos seus direitos fundamentais." (BRASIL, 1990, p. 10). E no Art. 53 do capítulo IV - Do Direito à educação, à cultura e ao lazer.

Os Parâmetros Curriculares Nacionais - PCN (BRASIL, 1997), também contemplam o multiculturalismo ao indicarem a importância de uma convivência democrática, que demanda zelo às múltiplas culturas ${ }^{1}$ constituintes da sociedade. Dispõem ainda, a aquisição de atitudes solidárias e cooperativas ratificadoras de rejeição às injustiças, de reconhecimento de aspectos individuais e socioculturais de povos e nações, e de uma posição crítica diante de "[. . .] discriminação baseada em diferenças de raça/etnia, classe social, crença religiosa, sexo e outras características individuais ou sociais; [...]" (BRASIL, 1997, p. 143). A finalidade do documento é ressaltar o valor da diversidade cultural, visível na originalidade e no pluralismo identitário que particularizam os grupos e as sociedades humanas tão importantes para a humanidade; e da etnocultura como elementos essenciais e inerentes à identidade nacional.

Espera-se que as escolas, como centros formadores e alinhadas aos dispositivos legais, auxiliem os alunos na construção e conscientização de sentimentos positivos e elevados dirigidos a outrem, como a empatia e a solidariedade; e criem meios de superação de sentimentos negativos e/ou desqualificadores, como o preconceito e as ações discriminatórias. Além disso, almeja-se que atentem para a valorização de um grupo em detrimento de outros, a cidadania para poucos, o desrespeito aos direitos humanos, o racismo e o segregacionismo. A imigração e o respeito a outros povos que aqui desembarcam estão atrelados aos mesmos dispositivos.

O equilíbrio dos PCNs nem sempre condiz com a realidade de muitas escolas públicas e coloca em dúvida seus fins, em específico, ao expor hostilidades, mal-estares e intransigências que iluminam traços pessoais e singularidades que atravessam ensinamentos e aprendizados. Esses traços podem configurar-se como ocorrências tensivas insuperáveis, visto constituírem-se como manifestações subjetivas fruto do dinamismo entre o mundo interno e o mundo externo do sujeito, com potencial para obstaculizar e/ou propiciar o desenvolvimento cognitivo-emocional.

Os movimentos migratórios (re)configuram as feições de qualquer coletividade e estão condicionados a aceitação dos receptores capazes de estabelecer quadros excludentes: 
[...] no caso da segregação, através do afastamento, da manutenção de uma distância topológica; no caso da marginalização, através da manutenção do indivíduo à parte de um grupo, de uma instituição ou corpo social; no caso da discriminação, através do fechamento do acesso a certos bens ou recursos, certos papéis ou status, ou através de um fechamento diferencial ou negativo. (JODELET, 2001, p. 53)

A descrição de Bourdieu (1998, p. 11), ao referir-se aos imigrantes, traduz o lugar (des)ocupado em que se encontra a maioria e em qualquer localidade: “[...] Nem cidadão nem estrangeiros, nem totalmente do lado do Mesmo, nem totalmente do lado do Outro, o 'imigrante' situa-se nesse lugar 'bastardo' de que Platão também fala, a fronteira entre o ser e o não-ser social."

Ressalva-se, ainda, que a Lei Diretrizes e Bases da Educação Nacional (BRASIL, 1996, p. 23) sinaliza no Art. $3^{\circ}$ inciso IV o "respeito à liberdade e apreço à tolerância”. o "apreço à tolerância" não expressa e nem significa anuência e aprovação; é uma concessão em relação a algo ou alguém, do qual se tem restrições, discorda-se ou se quer distância; é suportar e sustentar o insuportável e o insustentável presentificado no outro.

\section{Tolerância, preconceito e ações marginalizadoras}

A contextualização histórica empreendida por Bethencourt (2018) define como marco ocidental da imposição hierárquica religiosa a conquista da Espanha pelos árabes, no ano de 711, que oferecia a ideia de exercitar uma nova mentalidade e uma vida diferenciada das praticadas pelos cristãos opressores da época, sendo a tolerância um dos seus princípios. Contudo, os esforços não produziram os efeitos esperados e viu-se a progressão do preconceito e de repetidas conflagrações político-religiosas, fabricantes de odiosidades fecundas, que originaram o termo étnico, no século XIII, derivado do latim cristão ethnicus (pagão) e do grego ethnos (povo, nação ou raça).

Aos poucos, a terminologia converteu-se em categorização, com a inserção de critérios de identificação, como o porte físico, o uso de joias, o comprimento dos cabelos e da barba, com a criação de novas nomenclaturas, como a diferenciação 
tipológica de africano, asiático, europeu. Vocábulos como inferioridade, estigma e segregação associados à ascendência, ao espaço físico, à profissão e à sociedade aderiram ao vernáculo e imputados aos dessemelhantes. A partir dos anos mil seiscentos, o incremento da comercialização escravista confirmou o deslocamento discriminatório da religiosidade para a cor da pele.

No século XVIII, os constantes conflitos incitaram eruditos a dissertar sobre a tolerância. John Locke (2003), em a Carta acerca da tolerância (1689-90), discutiu a separação entre o Estado e a Igreja, defendeu a liberdade de conscientização religiosa, recomendava caridade e boa vontade, e condenava a intolerância, sobretudo se acompanhada de violência. Voltaire (2017), publicou em 1763, o Tratado sobre a tolerância, com a intenção de explanar sobre a intolerância e inculcar e estimular comportamentos harmônicos. O filósofo avançou perante seus antecessores por pautar-se em comunidades centrais e periféricas para atestar o afastamento entre os homens, desde a Antiguidade até o Iluminismo, que resultou em preconceitos por ascendência étnica, religiosa e política geradoras de divisões, categorias e castas.

A finalidade voltairiana de pacificação religiosa aproximou-se das proposições de Locke e diferenciou-se ao supor que o conhecimento tornaria o mundo mais organizado e as racionalizações poderiam atenuar as selvagerias.

As aspirações de Locke e Voltaire foram frustradas, pelo que Morin (2005a) denominou de barbarismo antropológico humano e para quem a gênese da questão está no "[...] lado demens, produtor de delírio, de ódio, de desprezo e daquilo a que os Gregos chamavam a Hybris, a desmedida" (p. 10), como efeito do rompimento das barreiras, censuras e/ou inibições psíquicas.

A desmedida não é independente e órfã. Tem seu complemento no lado sapiens, que deveria auxiliar contra a barbárie, mas sapiência e razão não são suficientes, porque o homem congrega também afetos e emoções que tendem a interditar ou transpassar a lógica, que pode embargar a sabedoria e exaltar a loucura ou embargar a loucura e exaltar a sabedoria, a depender das influências subjetivas. Estas singularidades deixam marcas, imprintings, ${ }^{2}$ que se mantêm por toda vida, porque são registrados e armazenados na memória e contêm uma energia desestabilizadora persistente.

Um locus expressivo desse fenômeno é a escola, onde as conexões são emergentes, desvendadas no dia a dia e no enraizamento de convicções, crenças, 
certezas e fantasias de cada membro da comunidade, que buscam, como adverte Candau (2011), equiparações monoculturais e homogeneizantes.

\section{0 "estrangeiro" na escola: observações e análises}

Apresentam-se, a seguir, os resultados parciais de uma pesquisa ${ }^{3}$ de abordagem qualitativa em andamento, que objetivou observar e analisar as relações interpessoais e educativas entre docentes e alunos imigrantes bolivianos e descendentes de bolivianos (denominados a partir daqui bolivianos) e entre estes e os demais alunos adolescentes do ensino fundamental II, dos $8^{\circ}$ e $9^{\circ}$ anos, de uma escola estadual pertencente à Diretoria Regional de Ensino Centro.

As observações transcorreram em sala de aula de dois professores colaboradores, nas dependências escolares comuns, como pátio e corredores. Procurou-se identificar os principais componentes do universo pesquisado, assinalar com exatidão seus fracionamentos e realçar a existência ou não de intercâmbio grupal (GIL, 2002).

As classes contavam em média 35 alunos e a variação sequente de transferências, ausências e desistências. Em cada uma das turmas encontram-se oito alunos bolivianos no $8^{\circ}$ e cinco no $9^{\circ}$ ano.

A instituição oferece refeições no intervalo das 9h30min e o prato do dia, em geral, é composto de arroz, feijão, uma proteína e legumes servidos pelas merendeiras e supervisionadas pelo diretor. A alimentação é satisfatória, pode ser repetida e os bolivianos o fazem com regularidade, feito que reforça as condições de vida que enfrentam.

As observações confirmaram um dado importante, constatado em investigação anterior na mesma escola: os bolivianos são assíduos, atentos às aulas, disciplinados, respeitosos, uniformizados, limpos e seus pais são exigentes e participativos na educação formal de seus filhos.

Nas aulas ministradas nos $8^{\circ}$ e $9^{\circ}$ anos pelo mesmo professor, que será identificado como Docente A (DA), as atividades eram programadas com antecedência e resumiam-se em seminários, debates e provas orais. Nas aulas do segundo professor, que se denominará Docente B (DB), para o $9^{\circ}$ ano, como nenhum aluno se sentia obrigado ou lhes era imposta a participação efetiva às aulas, havia dispersão e as bolivianas dirigiam-se para uma quadra descoberta 
até o término da aula; o único rapaz boliviano integrou-se ao futebol, depois de incentivado pelo DB.

A didática de DA, nas duas turmas, baseava-se em uma metodologia participativa e impunha pesquisas acadêmicas face às programações. Nestas ocasiões, os bolivianos demonstravam significativa dedicação e preocupação com as apresentações, embora o interesse da classe à demanda fosse discreto. As apresentações, como dos demais colegas, repetiam as mesmas narrativas concernentes ao tema predeterminado, com exploração sistemática dos mesmos sítios da rede mundial de computadores e um padrão seguidos por todos: alunos à frente lendo o trecho escolhido impresso ou em celulares. A leitura dos alunos do $8^{\circ}$, independentemente da origem, era inaudivel, com intensas dificuldades e os deslizes residiam em palavras desconhecidas. Não foi percebido sotaque espanhol dos bolivianos.

O comportamento de cinco alunas bolivianas do $8^{\circ}$ ano era idêntico em todas as aulas, com cabeça baixa, sentadas nas primeiras carteiras, caladas, respondendo quando inqueridas e executando as tarefas solicitadas sem contestação. Apenas uma era bastante próxima das demais e dispersiva como consequência de conversas paralelas. Os alunos bolivianos sentavam-se mais ao centro e um tentava interagir com os não-bolivianos que resistiam em incluí-lo.

As atitudes disciplinadas e/ou temerosas dos bolivianos são confirmadas por outros professores, em comentários isolados. Há um aparente resguardo, um sentimento de não-pertencimento de quem não se sente cidadão e nem estrangeiro, situando-se em um lugar ilegítimo e, no limite, entre o ser e o não-ser social. Isto é percebido nos intervalos das aulas, momentos em que se agrupavam e isolavam-se no vão da escada da área comum ou na quadra descoberta, para conversar, trocar alimentos, estarem juntos para serem; e escondiam-se e apartavam-se daqueles que os aparta, porque perto deles não são. Aliás, a fisionomia, o físico, os cabelos põem em suspeição a nacionalidade: boliviana ou brasileira?

As legislações inerentes à educação escolar são parcialmente atendidas na instituição. O que significa dizer que normas e princípios socioeducativos e culturais que regem a atenção à infância e à juventude são respeitados em alguns aspectos e desrespeitados em outros. Identificou-se do Art. 5 das Disposições Preliminares do ECA a segregação dos bolivianos, embora existam projetos pedagógicos vinculados às diferenças, como os voltados ao gênero, à negritude e a naturalidade, mas algum associado a nacionalidades e culturas. Esse fato anuncia descuido legal materializado na clivagem física que induz agrupamentos 
entre pares de origem latina, circunstância que confere identidade individual e coletiva, e os distancia de constrangimentos.

0 atendimento do Art. 53, do ECA, que trata do respeito do professor para com o aluno é duvidoso e dirigido com exclusividade aos alunos não-bolivianos, que resistem em entrar em sala ou tentam sair antes do término das aulas. É possível classificar as reações de alguns educadores como desmedidas, em virtude de repreensões e descortesias exasperadas dirigidas aos adolescentes que, ao cabo, estimulam respostas intensas e agressivas. Poucos alunos contestaram os processos avaliativos e os que o fizeram foram desqualificados. Os bolivianos não questionaram as avaliações e suas notas, até porque são sempre os melhores das turmas.

Nessa direção, e digno de atenção, foi o comentário de membros da comunidade: "bolivianos não tomam banho e não têm higiene". Sabe-se que o hábito do banho diário não é comum a todos os povos, mas no caso dos bolivianos são condições preponderantes ao encurtiçamento e a permissão de uma única ducha por dia, com o agravante de se quiserem mais deverem pagar taxas extras; o trabalho extenuante na "Feira da Madrugada", atividade desempenhada por vários a partir das 24 horas, e a posterior jornada escolar, sem dormir e sem alimentação; e o serviço de entrega ou condução de mercadorias antes e depois das aulas, expondo-os a fatigantes afazeres como meio de auxílio familiar e à vulnerabilidade do entorno. Pode-se avaliar a verbalização como preconceituosa e discriminadora, por proceder de um formador pouco sensível às situações degradantes do alunado. Ao se desconsiderar esses eventos, fere-se também a legislação e se revela a intolerância.

As observações admitem inferências acerca das emoções e sensibilidades dos educadores. DB demonstrou atitudes ambivalentes ao referir-se aos bolivianos e comentar que os achava estranhos, desconfiados e arredios, e ao buscar a agregação do aluno do $9^{\circ}$ ano a participar. Nesta situação, o abismo entre bolivianos e não bolivianos foi atenuado e, aos poucos, o aluno passou a compartilhar das atividades. A presença da pesquisadora talvez tenha ocasionado reações contraditórias no início dos procedimentos, mas com o passar do tempo e os diálogos durante as aulas, notou-se concreta preocupação com o destino dos bolivianos seja pela escassez de trabalho, o ambiente em que vivem ou o quadro socioeconômico precário.

O episódio do compartilhamento associado às posturas agregadoras permite pensar em uma atitude assimilacionista de $\mathrm{DB}$, por integrar o boliviano. A base 
de superioridade do grupo, contudo, não foi alterada, pois era permitida enquanto ocupante de um lugar determinado.

DA revelou-se compromissado com o ensino, perseverante e preocupado em orientar os alunos adolescentes quanto às relações interpessoais, as responsabilidades, a formação superior e a dedicação aos estudos. Contudo, parecia escapar-lhe a particularidade de ser boliviano, "imigrante", e restar a assiduidade, o cumprimento dos trabalhos e a disciplinarização como obrigação. Essa indiferença sugere uma diafaneidade que os ultrapassa e está para além da frequência, efetuação de tarefas ou da obediência, que aponta para a imperceptibilidade dos bolivianos, não obstante fossem respeitados como todos os outros. A didática das aulas sobressaía pela fortuita correção dos erros de leitura e pela desobrigação de execução das atividades propostas, como nas aulas de DB, apesar de comporem as avaliações trimestrais.

Não se percebeu hostilidades ou conflitos evidentes conduzidos aos alunos bolivianos pelos colegas, e tampouco quaisquer dinâmicas inclusivas que pudessem facilitar as inter-relações. Alguns movimentos assimilacionistas foram testemunhados, mas ratificaram posições hierarquizadas, pois os que estão em maior número dominam os espaços classificados como seus, interceptando possíveis aproximações.

Os PCNs são contemplados na presença da heterogeneidade que, todavia, não significa uma convivência democrática nos termos de Candau $(2012 ; 2011)$ e do próprio documento, haja vista que atitudes solidárias, cooperativas e integradoras reguladas pela raça/etnia e segmento social compareceram entre os iguais e cada qual em seu território e em seu lado da fronteira.

Não foram percebidas do DA, do DB e dos alunos o reconhecimento das individualidades e singularidades do grupo boliviano, o que retrata a desvalorização das experiências, vivências e dos imprintings adquiridos no percurso escolar, que tanto têm propriedade de bloquear como liberar mágoas, pesares, dores desfavoráveis à reciprocidade e à harmonia com brasileiros, e intervir nos desenvolvimentos cognitivo e emocional. No entanto, a possibilidade de superação se dá com o fortalecimento egoico e a ecologia da ação, que pode provocar efeitos contrários dos expectados, como a suplantação de adversidades.

A tolerância, como preconizada na LDB, sublinhada por Locke como caritativa e não violenta, e por Voltaire no incitamento da razão, está escamoteada. É possível assegurar que a intolerância se encontra em estado latente em 
não-bolivianos, porque os bolivianos são imperceptíveis e ofuscados pelo próprio empenho educacional e pela inexistência de planos para sua efetiva inclusão.

o sapiens/demens, a razão e a loucura, como uma das características humanas, manifestaram-se na escola em tela e mostraram que não podem ser ocultadas, por escaparem ao controle da consciência.

\section{Finalizando}

As observações alcançaram os objetivos e desvendaram julgamentos preconceituosos, translucidez de bolivianos, distanciamento entre bolivianos e docentes, e desunião de bolivianos e demais alunos. Tais relações possibilitam somente uma integração paliativa, sem alteração da hegemonia social e da situação de exclusão na inclusão. A imperceptibilidade desses alunos é evidente e não se vislumbram estratégias para modificação do cenário que aprofunda prejulgamentos, pois os controles racionais não são reinantes e estão presos a comandos subjetivos. "A Afetividade intervém no desenvolvimento e nas manifestações de inteligência" (MORIN, 2005b, p. 121).

A escola estudada preenche, em parte, os requisitos de edificação e conscientização de sentimentos elevados dirigidos aos diferentes, pois claudica quanto a diversidade cultural estrangeira, que poderia agregar e acrescentar conhecimentos e saberes, e abrandar as desconfianças.

O assimilacionismo é o único eixo do multiculturalismo presente e verificado na instituição. Entende-se que a reversão situacional estaria na elaboração de projetos pedagógicos interculturais, que incluíssem todos os grupos que constituem o âmbito escolar e por intermédio da conscientização e da racionalidade estabelecessem processos construtivos e reconstrutivos permanentes colocando os bolivianos em convívio.

\section{Notas}

1 "O conceito de cultura abarca toda manifestação que emana das trocas sociais e é transmitida através das gerações. A língua, a música, a arte, o artesanato, entre tantas outras, são manifestações culturais. A língua, bem cultural e patrimônio coletivo, reflete a visão de 
mundo de seus falantes e possibilita que as trocas sociais sejam significadas e ressignificadas." (PCN+, 2002, p. 63).

2 Imprinting: "marca indelével imposta, primeiro, pela cultura familiar e, depois, pela cultura social, que se mantém na vida adulta" (MORIN, 2005b, p. 302).

3 A referida pesquisa intitulada "Diversidade cultural no espaço escolar: implicações no ensino, na aprendizagem e nos processos de subjetivação" é parte de uma investigação maior levada a cabo em projeto de Pós-Doutoramento realizado na Universidade Presbiteriano Mackenzie (UPM), no Programa de Educação, Arte e História da Cultura (Each) sob supervisão do professor Dr. João Clemente de Souza Neto. O projeto de pesquisa foi submetido ao Comitê de Ética da Universidade Nove de Julho e aprovado sob no 86682518.6.0000.5511.

\section{Referências}

BETHENCOURT, Francisco. Racismos: das cruzadas ao século XX. Trad. Luís Oliveira Santos, João Quina Edições. São Paulo: Companhia da Letras, 2018.

BOURDIEU, Pierre. Prefácio: Um analista do Inconsciente. In: SAYAD, A. A imigração ou os paradoxos da alteridade. Trad. Cristina Murachco. São Paulo: Edusp, 1998.

BRASIL/SEMTEC. PCN+Ensino Médio: Orientações educacionais complementares aos Parâmetros Curriculares Nacionais. v. 1: Linguagem, códigos e suas tecnologias. Brasília/ DF: MEC/SEMTEC, 1997. Disponível em: < portal.mec.gov.br/seb/arquivos/pdf/02Linguagens. pdf>. Acesso em: 18 jan. 2016.

BRASIL. Estatuto da criança e do adolescente: Lei 8.069, de 13 de julho de 1990. 3.ed. Brasília: Câmara dos Deputados, Coordenação de Publicações, 1991.

BRASIL. Lei de Diretrizes e Bases da Educação Nacional. Brasília: Senado Federal, Coordenação de Edições Técnicas, 1996. Disponível em http://www.planalto.gov.br/ccivil_03/ Leis/L9394.htm. Acesso em 20 janeiro 2017.

CANDAU, Vera M. Multiculturalismo e educação: desafios para a prática pedagógica. In: CANDAU, V. M.; MOREIRA, F. A. (orgs). Multiculturalismo: diferenças culturais e práticas pedagógicas. 7. ed. Petrópolis: Vozes, 2011.

CANDAU, Vera M. F. Diferenças culturais, interculturalidade e educação em direitos humanos. Educ. Soc., Campinas, v. 33, n. 118, p. 235-250, mar. 2012. Disponível em $<$ http://www.scielo.br/scielo.php?script=sci_arttext\&pid=S0101-73302012000100015\&lng=p t\&nrm=iso $>$. Acesso em 30 maio de 2018.

GIL, Antonio C. Como elaborar projetos de pesquisa. 4. ed. São Paulo: Atlas, 2002.

JODELET, Denise. Os processos psicossociais de exclusão. In: SAWAIA, B. As artimanhas da exclusão. Análises psicossociais e ética da desigualdade social. 2 ed. Petrópolis: Vozes, 2001.

LOCKE, John. Carta acerca da tolerância. Trad. Anoar Aiex e E. Jacy Monteiro. Coleção “Os pensadores". 3. ed. São Paulo: Abril, 2003. 
MORIN, Edgar. Cultura e barbárie europeias. Trad. Ana Paula de Viveiros. Colecção Epistemologia e Sociedade. Lisboa: Instituto Piaget, 2005a.

O método 5: a humanidade da humanidade. Trad. Juremir M. da Silva. 3. ed.

Porto Alegre: Sulinas, 2005b.

MOREIRA, Antonio F.; CANDAU, Vera M. (Org.). Multiculturalismo: diferenças culturais e práticas pedagógicas. Apresentação. 7. ed. Petrópolis: Vozes, 2011.

VOLTAIRE (François Marie Arouetad). Tratado sobre a tolerância. Trad. Leandro Cardoso M. da Silva. São Paulo: Edipro, 2017.

recebido em 15 jun. 2018 / aprovado em 20 jul. 2018

Para referenciar este texto:

DIAS, E. T. D. M.; SOUZA NETO, J. C. Multiculturalismo em educação: o atendimento escolar de alunos bolivianos e descendentes. Dialogia, São Paulo, n. 29, p. 83-94, mai./ago. 2018. Disponível em: <https://doi.org/10.5585/Dialogia.n29.8802>. 